\title{
Isolated Kaposi sarcoma of the stomach
}

A 54-year-old man was admitted to a regional hospital with fever, weight loss, and malaise. He was found to have infection with the human immunodeficiency virus (HIV). An upper gastrointestinal endoscopy revealed multiple gastric submucosal nodules; biopsies of the nodules were taken, the histopathology of these being reported as gastric adenocarcinoma. The patient was therefore referred to our unit for further evaluation.

On admission, his physical examination was unremarkable except for the presence of cervical lymphadenopathy. Laboratory tests revealed only mild normochromic anemia. We performed an upper gastrointestinal endoscopy and found multiple red-purple vascular submucosal nodules distributed from the cardia to the prepyloric region, which varied in size from 4 to $20 \mathrm{~mm}$ ( Fig. 1; Video 1 ). Multiple biopsies were taken with cold forceps, but the histopathology of these was unremarkable, showing only chronic gastritis. It was therefore decided to proceed to endoscopic mucosal resection (EMR). One of the lesions was raised up with $4 \mathrm{~mL}$ of adrenalin (dilution with saline $1: 5000$ ) and a mucosectomy was performed without complications ( Fig. 2). Histopathologic examination was pathognomonic of Kaposi sarcoma, showing spindle cell proliferation and vascular slits with hemorrhage. The patient was referred to the Infectious Diseases Hospital for further treatment.

Kaposi sarcoma is a multicentric vascular tumor, which accounts for $60 \%$ of tumors in patients with acquired immune deficiency syndrome (AIDS) [1]. Involvement of the gastrointestinal tract by Kaposi sarcoma can precede or be synchronous with the development of skin lesions or may

\section{Video 1}

Endoscopic examination of a 54-year-old man with acquired immune deficiency syndrome (AIDS) showing the multiple submucosal nodules in the gastric fundus, subcardiac region, and proximal part of the corpus.
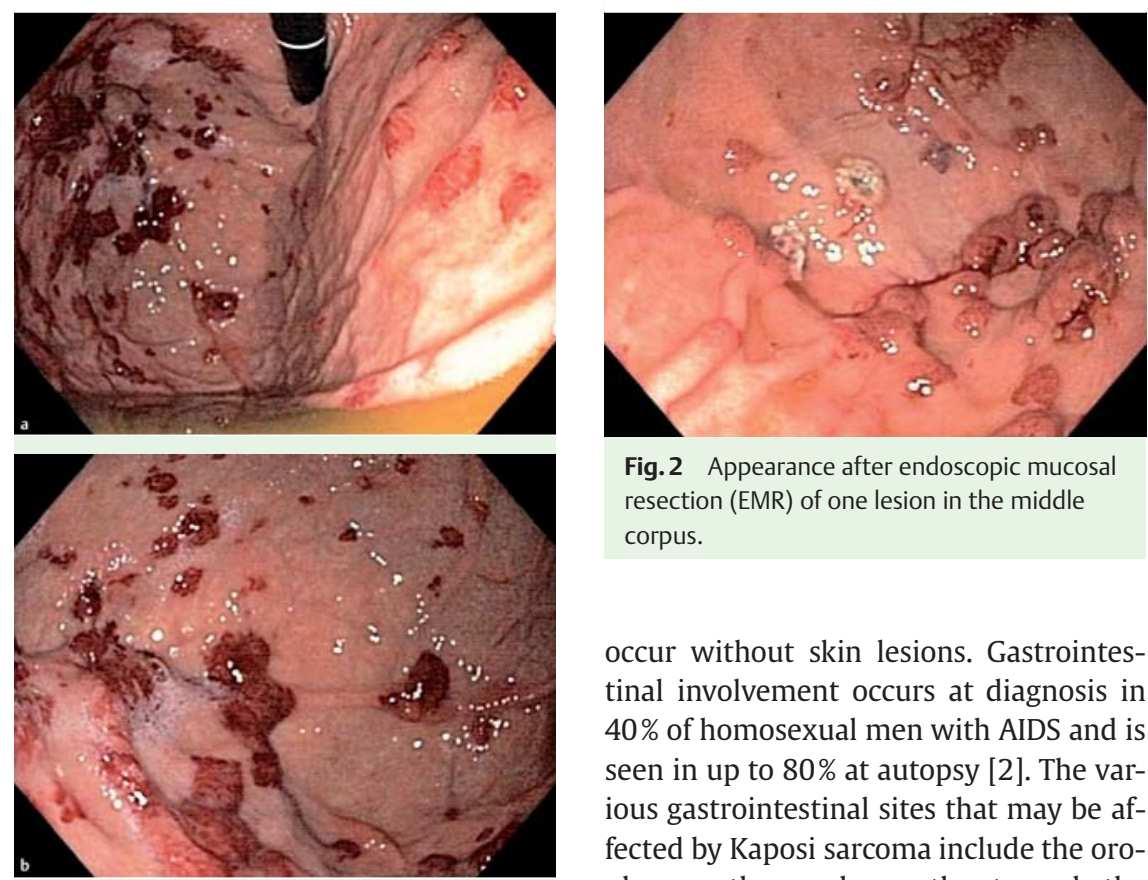

Fig. 2 Appearance after endoscopic mucosal resection (EMR) of one lesion in the middle corpus.

occur without skin lesions. Gastrointestinal involvement occurs at diagnosis in $40 \%$ of homosexual men with AIDS and is seen in up to $80 \%$ at autopsy [2]. The various gastrointestinal sites that may be affected by Kaposi sarcoma include the oropharynx, the esophagus, the stomach, the liver, and the small and large bowel [1].

The endoscopic findings in gastric Kaposi sarcoma can vary from lesions similar to a peptic ulcer to the more typical purple vascular submucosal nodules covered with a thin layer of overlying mucosa. Lesions are usually asymptomatic but can present with gastrointestinal bleeding and gastric outlet obstruction [3]. An adequate histologic sample is critical for diagnosis. Cold forceps biopsies are usually sufficient but may be inadequate for the diagnosis of stromal proliferation tumors [4]. In such cases, diagnosis may be possible only after EMR of a gastric nodule.

Endoscopy_UCTN_Code_CCL_1AB_2AD_3AB

Competing interests: None 
P. Markos, H. Ivekovic, R. Pulanic, B. Vucelic

Division of Gastroenterology and Hepatology, Department of Internal Medicine, University Hospital Zagreb, Zagreb, Croatia

\section{References}

1 Danzig JB, Brandt LJ, Reinus JF et al. Gastrointestinal malignancy in patients with AIDS. Am J Gastroenterol 1991; 86: 715-718

2 Friedman SL, Wright TL, Altman DF. Gastrointestinal Kaposi sarcoma in patients with acquired immunodeficiency syndrome: endoscopy and autopsy findings. Gastroenterology 1985; 89: 102

3 Lin CH, Hsu CW, Chiang YJ et al. Esophageal and gastric Kaposi's sarcomas presenting as upper gastrointestinal bleeding. Chang Gung Med J 2002; 25: 329-333

4 Sakagami J, Sogame Y, Kataoka Ket al. Endoscopic resection for the diagnosis of visceral Kaposi's sarcoma. J Gastroenterol 2005; 40 : 98-103

\section{Bibliography}

DOI http://dx.doi.org/

10.1055/s-0031-1291670

Endoscopy 2012; 44: E112-E113

(c) Georg Thieme Verlag KG

Stuttgart · New York

ISSN 0013-726X

\section{Corresponding author}

\section{P. Markos, MD}

Division of Gastroenterology and Hepatology Department of Internal Medicine

Clinical Hospital Center

Kispaticeva 12

10000 Zagreb

Croatia

Fax: +385-1-2420100

pave.markos@inet.hr 